\section{Summary of: Piloting a local dental network across Hampshire and Isle of Wight Primary Care Trusts}

\author{
J. H. John, ${ }^{* 1}$ V. Easterby-Smith ${ }^{2}$ and K. R. Percival ${ }^{3}$
}

\section{FULL PAPER DETAILS}

${ }^{1}$ Consultant in Dental Public Health, Public Health England (Wessex), ${ }^{2}$ Clinical Commissioning Lead (Dental) and Dental Practice Adviser, NHS England (Wessex), Oakley Road, Southampton, S016 4GX, ${ }^{3}$ Honorary Secretary, Hampshire and Isle of Wight Local Dental Committee, 24 Veryan, Fareham, Hants, P014 1NN

${ }^{*}$ Correspondence to: Dr Jeyanthi H. John

Email: Jeyanthi.John@phe.gov.uk

Online article number E10

Refereed Paper - accepted 10 June 2014

DOI: 10.1038/sj.bdj.2014.759

British Dental Journal 2014; 217: E10

Aim To pilot a local dental network (LDN) within the Hampshire and Isle of Wight region. Method An LDN Coordinating Group was set up, which was chaired by the local consultant in dental public health and included representatives from dental commissioning and performance management teams, dental practice advisory team, finance, Oxford and Wessex Dental Deanery and the Hampshire and Isle of Wight Local Dental Committee. The LDN successfully led the organisation of a leadership training course for local dentists, and produced recommendations for local oral surgery and orthodontics care pathways. Key to the success was the collaboration achieved between the commissioners, local postgraduate dental deanery and local dental committee. Results There were challenges associated with involving non-salaried dental practitioners without a source of funding, and with communicating with the wider dental community. Conclusions The new Wessex LDN needs to be adequately resourced and integrated into the local commissioning structure, as well as the wider health system, to function effectively. Most importantly, the LDN needs local dental professionals to embrace the opportunities for leadership and use their skills to inform and influence local dental commissioning for the benefit of the local population.

\section{EDITOR'S SUMMARY}

The organisation of healthcare and the provision of that care could not be more different. To the uninitiated the difference may seem to be semantic but on the ground the complexities are manifold. Why should this be?

To some extent the complication revolves around the third party payment system. In a situation where a patient pays the clinician directly then the service can be proposed, accepted and carried out with due legal and ethical considerations but with little else in the way of bureaucracy, accountancy, approval and so forth. The introduction of a third party, in this case the NHS, doesn't seem as if it could cause havoc; but it does. With the system (the first clue to potential complications) different providers have various contractual arrangements and one consequence at least is that no one seems to have an overall control sufficient to order everyone else into line; whatever that line might be and whoever's role it is to decide it. The sprinkle of mayhem on top of this indigestible confection is that there is no funding for anyone to do anything about it. So, for me the most telling sentence in this paper in respect of making intra-professional progress is, 'However, for selfemployed GDPs managing their business, the priority is always to deliver on their contracted activity.'

So, it would seem to me that the authors of this paper were, and are, in an almost impossible situation in attempting to establish a local dental network, which indeed they evidence here. It is of enormous credit to them that they have managed to get as far as they have to date and intend to continue by taking the challenges encountered here and aiming to overcome them.

The idea of local commissioning advised by a clinical leadership consensus seems to make a good deal of sense in terms of appropriate allocation of finite, third party, funding. But this part of the system itself needs funding since it is, to quote the authors once again, using in my opinion an unnecessarily polite euphemism, 'resourceintensive'. This paper records yet another stage in a never ending series of transitions.
The full paper can be accessed from the $B D J$ website (www.bdj.co.uk), under 'Research' in the table of contents for Volume 217 issue 5.

Stephen Hancocks Editor-in-Chief DOI: 10.1038/sj.bdj.2014.790 


\section{TO ACCESS THE BDJ WEBSITE TO READ THE FULL PAPER}

- BDA Members should go to www.bda.org.

- Click the 'login' button on the right-hand side and enter your BDA login details.

- Once you have logged in click the 'BDJ' tab to transfer to the BDJ website with full access.

IF YOUR LOGIN DETAILS DO NOT WORK:

- Get a password reminder: go to www.bda.org, click the login button on the right-hand side and then click the forgotten password link.

- Use a recommended browser: we recommend Microsoft Internet Explorer or Mozilla Firefox.

- Ensure that the security settings on your browser are set to recommended levels.

IF YOU HAVE NOT YET SIGNED UP TO USE THE BDA WEBSITE:

- Go to www.bda.org/getstarted for information on how to start using the BDA website.

\section{COMMENTARY}

This paper provides an excellent overview of the challenges faced in the establishment of local professional networks (LPNs) following the Health and Social Care Act (2012) and the NHS reforms.

The approach adopted by the team in the SHIP Primary Care Trust (PCT) cluster reflected similar work across other localities in England. During transition the NHS Commissioning Board (now NHS England) actively engaged with PCT clusters and pilot LPNs to share knowledge on a national level with respect to local/national challenges. A major part of this process was to develop innovative ways of working within current regulatory structures utilising current (and occasionally diminishing) resources. Where this was most successful, it was generally as a result of strong leadership from consultants in dental public health and experienced commissioners 'holding the ring' while clinicians developed clinical leadership skills and knowledge. Many localities adopted similar approaches to SHIP, largely driven by the challenges unique to that locality in order to achieve a common approach at a national level.

The concept of clinical leadership is not new, but our medical colleagues have had greater exposure. The authors recognised this as a major challenge to developing effective clinical leadership. Engagement with primary care clinicians was challenging, particularly where there was no additional funding available - it is commendable to observe primary care providers taking an interest in this process and developing new skills, without any financial reward to themselves. These clinicians were able to adopt a broader view of the dental profession beyond the detail of their own contractual arrangements. It is clear for this model to be sustainable there needs to be appropriate funding to support NHS England area teams and their LDNs together with continued support and advice from consultants in dental public health from Public Health England. Flexibility in current and future contractual arrangements and remuneration will be needed to enable innovation to deliver improvements in quality and value for money within NHS England area team LDNs and the work streams delivered in primary care.

Work streams in this LDN (and other LDNs nationally) have demonstrated effective models, with primary care clinicians working with commissioners and consultants in dental public health at the centre of advisory and decision making processes.

This paper provides an example of how LDNs can function effectively. It also serves to illustrate how primary care clinicians can be at the heart of this process, hopefully raising the awareness of the profession and encouraging more clinicians to step forward in these roles.

\section{Dr Michael McGrady \\ StR/Honorary Lecturer in \\ Dental Public Health}

Public Health England/University

of Manchester School of Dentistry

\section{IN BRIEF}

- Describes the process of establishing and testing a pilot local dental network (LDN) within Hampshire and the Isle of Wight.

- Discusses the difficulties of involving general dental practitioners without a source of funding, and communicating with the wider dental community.

- Considers challenges and opportunities faced by the new LDN, such as gaining credibility within the health system and influencing the oral health agenda.

\section{AUTHOR QUESTIONS AND ANSWERS}

1. Why did you undertake this research? LDNs are a key feature of the new health system with a remit to provide clinical leadership to inform local dental commissioning. This is a new concept and there was a national call for pilots to understand how this might work within local areas. We established our pilot LDN in response to this as we believed that the learning would be helpful to us locally and contribute to the national knowledge base. We already had a local dental clinical leadership team in place to provide clinical advice and support to local dental commissioning. There was an opportunity to develop and test this successful model to assess if it could be adapted to the requirements of the new health system. We were also keen to understand, early on, what the challenges and priorities might be for a local LDN.

\section{What would you like to do next in this} area to follow on from this work?

The pilot identified a number of challenges that need to be addressed, including limited budgets, communicating with the wider dental community and developing local clinical leadership. The Wessex Area Team is currently establishing an LDN, using the learning from this pilot and other similar pilots from around the country. This is a developmental project and we hope to evaluate the impact of the LDN over the next year. It will be important to assess the credibility the LDN achieves in the new health system and its degree of influence local dental commissioning. There are initial plans to develop a list of projects that can be prioritised and then tracked using programme management approaches. Ultimately the greatest value of the LDN will be whether it is able to achieve and use its influence to impact on oral health outcomes in local communities, within the very limited financial resources available. 